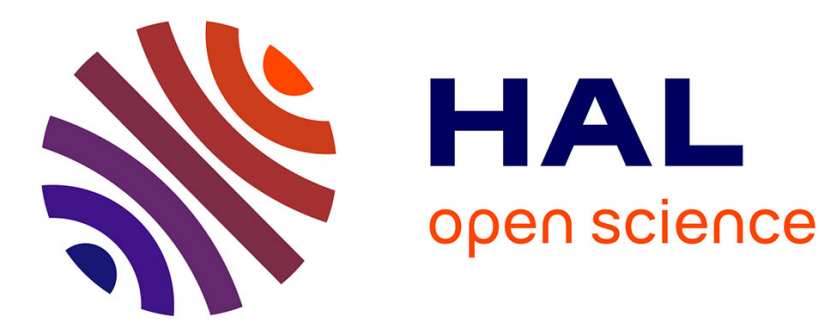

\title{
ICT Demand Behaviour: an International Comparison
} Gilbert Cette, Jimmy Lopez

\section{To cite this version:}

Gilbert Cette, Jimmy Lopez. ICT Demand Behaviour: an International Comparison. Economics of Innovation and New Technology, 2012, 21 (4), pp.397-410. halshs-01226444

\section{HAL Id: halshs-01226444 \\ https://shs.hal.science/halshs-01226444}

Submitted on 1 Dec 2015

HAL is a multi-disciplinary open access archive for the deposit and dissemination of scientific research documents, whether they are published or not. The documents may come from teaching and research institutions in France or abroad, or from public or private research centers.
L'archive ouverte pluridisciplinaire HAL, est destinée au dépôt et à la diffusion de documents scientifiques de niveau recherche, publiés ou non, émanant des établissements d'enseignement et de recherche français ou étrangers, des laboratoires publics ou privés. 


\title{
ICT demand behaviour: an international comparison
}

\author{
Gilbert Cette* and Jimmy Lopez**
}

\begin{abstract}
This study aims to provide some empirical explanations for the gaps in ICT diffusion between industrialized countries and especially between European countries and the United States. National macroeconomic panel data are mobilized for eleven OECD countries over the 1981-2005 period. The analysis is based on factor demand estimates. It provides some original results: (i) The impact on ICT diffusion is positive for the level of education and negative for market rigidities, and both increased over time (in absolute terms) until the middle of the 1990s; (ii) In each country, the price-elasticity of demand for ICT decreased (in absolute terms) over time, from 2 at the beginning of the 1980s to 1 in the middle of the 2000s.
\end{abstract}

Keywords: ICT; investment; factor demand; productivity; education; regulation.

JEL classification: E22, O47, O57, R24.

\section{Introduction}

A large body of literature (for example Shreyer 2000, Colecchia and Shreyer 2001, Pilat and Lee 2001, OECD 2002 and 2003, van Ark et al. 2002a and b, van Ark, O'Mahony and Timmer 2008, or Cette, Lopez and Noual 2005) has shown that the level of the diffusion of information and communication technologies (hereafter ICT) differs greatly across the main industrialized countries, the United States being the country where the diffusion appears to be the highest. The ICT capital coefficient (ratio of ICT capital stock to GDP in current prices) has risen over the last few decades in the major advanced countries, and stabilized in the last few years (Figure 1). This apparent stabilisation of ICT diffusion occurs at very different levels across all countries, the United States being the country with the strongest ICT diffusion, and the United Kingdom following close behind. Such gaps could have a major impact on levels of productivity gains and economic growth in the different countries analysed.

\footnotetext{
*: Banque de France and Université de la Méditerranée (DEFI).

**: Banque de France and Université de la Méditerranée (GREQAM).

The authors thank M. Juillard, G. Nicoletti, V. Spiezia and anonymous reviewers for their useful remarks.
}

The views expressed in this article are those of the authors and do not necessary reflect those of the institutions for which they work. 


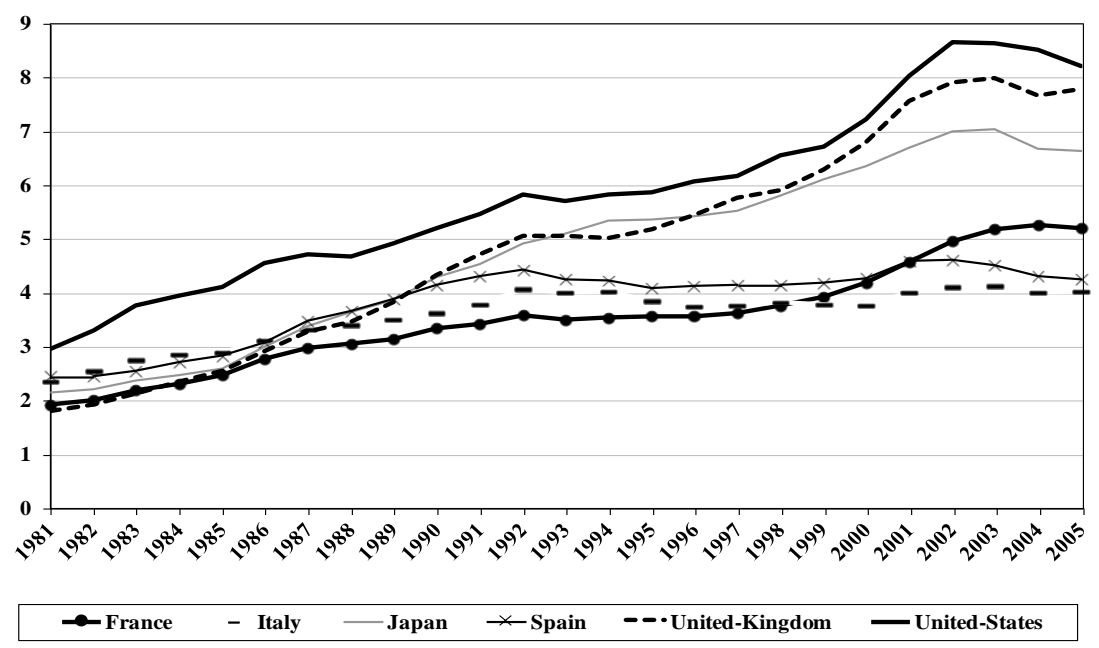

Figure 1. ICT capital coefficient (x 100), at current prices (ratio of ICT capital stock to GDP in current prices) Scope: the whole economy

Source: Authors calculations using the EU-KLEMS database.

Gust and Marquez (2000) suggest that the gaps in ICT diffusion between advanced countries, and in particular the European lag vis-à-vis the United States, are temporary and should gradually disappear. However, the stability, or even the widening, of ICT diffusion gaps between Europe and the United States over several decades would tend to contradict this theory.

A number of studies provide alternative explanations for the European ICT diffusion lag, using descriptive approaches (for example Antipa et al. 2007) or econometric investigations (for example Gust and Marquez 2004, Cette, Lopez and Noual 2005, Aghion et al. 2008, Arduini, Nascia an Zanfei, 2010, Haller and Siedschlag 2008, Siedschlag, Zhang and Smith 2009, or Lera-Lopez, Billon and Gil 2011). Two explanatory factors are often put forward: the level of education and market rigidities. ${ }^{1} \mathrm{An}$ efficient use of ICT generally requires firm reorganization and institutional flexibility, which can be restricted by excessively stringent regulations. Moreover, product market regulations can reduce competitive pressure and thus lower the incentives to use the most efficient production techniques. In addition, the use of ICT generally requires labour with a higher degree of skills than other production technologies. In the United States, there are relatively few market rigidities and the share of the working-age population with a higher education is greater than in other advanced countries (the market rigidities gap between the United States and other Anglo-Saxon countries remains quite small). These results and the lessons from these first analyses still need further consolidation and more indepth analysis.

The aim of this paper, following on from the above-mentioned analyses, is to appreciate the changes of the impact of ICT relative prices, of education levels in working age populations and of market rigidities on ICT diffusion levels. This impact is evaluated through an econometric estimation of a factor demand model. The data mobilized for this empirical investigation correspond to a country level panel which covers eleven OECD countries: Austria, Denmark, Finland, France, Germany, Italy, Japan, the Netherlands, Spain, the United Kingdom and the United States. The main data sources are the EU-KLEMS and OECD databases.

Our results confirm a negative impact of ICT relative price and of market rigidities and a positive impact of the education level of the working-age population on ICT diffusion. The original contribution of this paper to the existing literature is twofold. Firstly, the estimates show that the impact of the proportion of the population with higher education and of market rigidities on ICT diffusion increases with the level of ICT diffusion. Secondly, the estimates also show for each country a time decrease (in absolute terms) in the price elasticity of demand for ICT. This suggests that ICT

1 Antonelli, Krafft and Quatraro (2011) underline the impact of research in ICT sectors not only on ICT innovation but also on a country's ability to imitate ICT technologies. Education and market rigidities are important determinants of a country's research ability, hence our model could be presented as a reduced form including this mechanism. 
diffusion actually reflects two phenomena: a widening use of ICTs, and an intensification of their use by existing users. The first effect is gradually diminishing while the second remains supportive of ICT growth. The net result of these effects is a slowdown in ICT diffusion and a decrease in the price elasticity of ICT demand (in absolute terms).

After introducing the model used to characterise the demand for ICT and other production factors (2.), we present the estimates obtained from this model (3.) and end with some policy implications and concluding remarks (4.).

\section{The model}

We present the basic model (2.1.), the inclusion of the level of education and market rigidities in the equation (2.2.) and an alternative specification taking account of the possibility of coefficient changes (2.3.).

\subsection{The basic model}

Given the short temporal dimension, we estimate a static model corresponding to a long-term relationship on the basis of a simple and partially calibrated specification of factor demand. The ICT demand specification, very general, depends on the output and the ICT relative price:

$$
f_{k, t}=q_{k, t}+a 1 \cdot\left(c_{k, t}-p_{q k, t}\right)+c s t_{k}
$$

The logarithms of the variables are denoted by lower cases. For each country $\mathrm{k}$ and year $\mathrm{t}, f_{k, t}$ and $q_{k, t}$ are, respectively, the ICT factor and the gross domestic product, in constant prices; $c_{k, t}$ and $p_{q k, t}$ are, respectively, the ICT capital user cost and the gross domestic product deflator; a1 is the ICT elasticity of substitution vis-à-vis, simultaneously, the whole set of production factors and cst $_{k}$ are country fixed effects taking into account country heterogeneity. ${ }^{2}$

\subsection{Taking account of the level of education and market rigidities}

The estimated relationship is completed by adding indicators for the level of education and market rigidities to the list of explanatory variables. There are, at least, two reasons why an efficient use of ICT requires highly educated workers. First, as with every new or quickly evolving technology, workers need to be able to learn how it works, to deal with this new knowledge and to adapt together their work organization. Second, and maybe most important reason, even if ICT were no more an innovative technology, they could be complementary to high educated people. Indeed, according to Autor et al. (2006), ICTs are substitutes for repetitive tasks, so therefore complementary to nonrepetitive complex tasks, which are done by higher educated workers. Because an efficient use of ICT requires changes in the work organization, ICT diffusion could be growing with labour flexibility. In the same way, rent-seeking performance improvements grow with the level of competition and are then weakened by over-regulation of the product market. The preferred variable used to represent the level of education is the proportion of the population aged between 25 and 64 with at least some higher education (EDUC). To take better account of the effect of the level of education on the demand for ICT capital, we test a quadratic specification for this variable. Such a quadratic specification is suggested by the data (see Figure 2). For market rigidities, we use the OECD indicators of employment protection legislation (EPL) for the labour market and the OECD indicators of regulation in energy, transport and communications (ETCR) for the product market. ${ }^{3}$

2 This empirical specification, very intuitive, can also be deduced from a producer maximization program under weak assumptions, mainly the local approximation of the production function using a CES and constant returns to scale (see Appendix B).

3 For more information on EPL and ETCR see "OECD Employment Outlook", 1999, and Conway, Janod and Nicoletti, 2005. In order to facilitate the interpretation of the estimates, these indicators are re-scaled between $0-1$, with 1 for the strongest rigidity. 


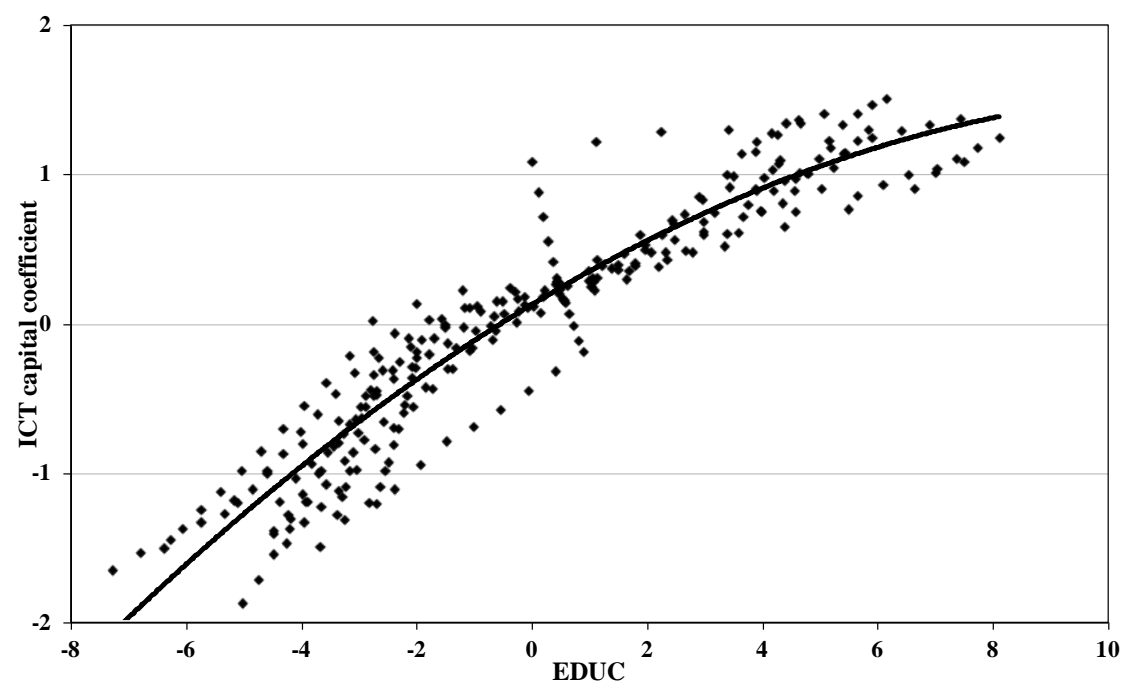

Figure 2. Education and ICT diffusion

Each observation corresponds to a country-year situation and is purged of country means. 11 countries and 25 years (1981-2005) are considered.

Education is the proportion of the population aged 25 to 64 with at least some higher education (EDUC). ICT diffusion is the ICT capital coefficient (ratio of ICT capital stock to GDP in current prices).

Both indicators of market rigidities often combine the following shortcomings: weak volatility and strong inter-correlation. These problems could impact the quality of the estimations. ${ }^{4}$ One solution is to introduce both of them alternatively in the estimated relationship. ${ }^{5}$ Another solution is to interact the market rigidity indicators. This interaction is preferred and is supported by a large body of literature showing the complementarities between markets regulations (see especially Amable and Gatti 2006, Koeniger and Vindigni 2003, Blanchard and Giavazzi 2003, Blanchard 2005, Aghion et al. 2008). Moreover, the indicator obtained by interacting the two indicators of market rigidity shows a stronger volatility than each indicator individually. The alternative introduction or interaction of the indicators are both presented.

Introducing education level and market rigidity indicators into the relationship (1) plus indicators of certain control variables leads to the first estimated relationship:

$$
\begin{aligned}
& f_{k, t}-q_{k, t}=a 1 .\left(c_{k, t}-p_{q k, t}\right)+a 2 . E D U C_{k, t}+a 2^{\prime} . E D U C_{k, t}^{2}+a 3 \cdot R^{2} G I D_{k, t}+ \\
& \sum_{i} b_{i, k} \cdot x_{i k, t}+c s t_{k}+u_{k, t}
\end{aligned}
$$

In this relationship, for each country $\mathrm{k}$ and year $\mathrm{t}$, the logarithm of the ICT capital coefficient (ratio of ICT capital stock to GDP in current prices), $f_{k, t}-q_{k, t}$, depends on: (i) the logarithm of the relative price of ICT as compared to the price of all other factors, $c_{k, t}-p_{q k, t}$, therefore the coefficient $a 1$ is the ICT elasticity of substitution vis-à-vis, simultaneously, the whole set of production factors; (ii) the level of education $E D U C_{k, t}$ and its square value $E D U C_{k, t}^{2}$, as well as the level of market rigidities $R I G I D_{k, t}$; (iii) some control variables, indicated by the term $\sum_{i} b_{i, k} \cdot x_{i k, t}$, in order to take into account the cyclical fluctuations (with the capacity utilisation rate CUR) and specific measurements errors (with the average age of ICT equipment AGE and the logarithm of the exchange rate chg); ${ }^{6}$ (iv) country fixed effects $\operatorname{cst}_{k}$; (v) error terms assumed to be identically and independently distributed $\left(u_{k, t} \sim>\mathrm{N}\left(0, \sigma^{2}\right)\right)$.

4 When introduced simultaneously the null hypothesis of multicolinearity could not be rejected.

5 As there are strong positive correlations between the market rigidity indicators, introducing both of them alternatively amounts to over-estimating each specific impact, as part of the explanatory power of the omitted indicator is carried forward to the present indicator.

6 For a discussion on these specific measurements errors see Cette, Lopez and Noual (2005). 


\subsection{Estimated equation with coefficients changes}

A second specification allows for changes in the parameters. The descriptive analysis, confirmed further by the estimation results, suggests important changes in the influence of some variables on ICT demand.

First, coefficient changes are suggested by Figure 3. This Figure shows the changes in the correlation between the level of education, the indicators of market rigidity and ICT diffusion. This pattern could explain the increase in the ICT diffusion gaps in the 1990s. Indeed the USA shows low market rigidities and a high level of education.

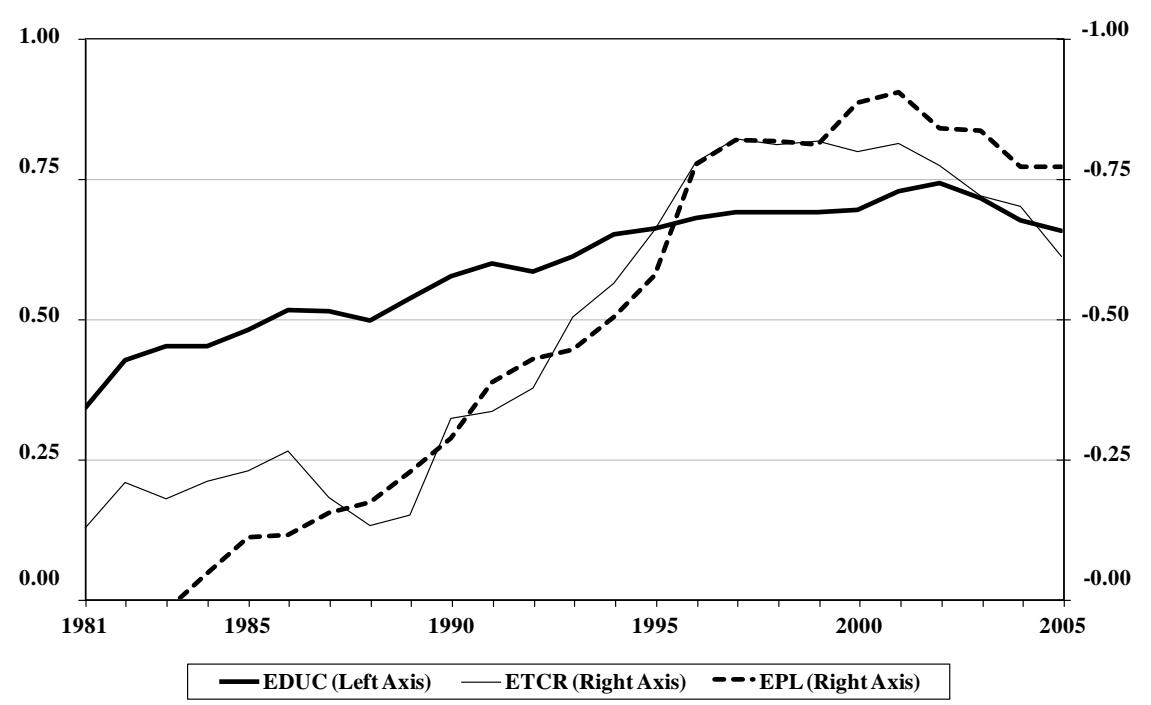

Figure 3. Cross-country correlations of the ICT capital coefficient with the level of education (EDUC) and product and labour market rigidities (respectively ETCR and EPL)

EDUC is the share of the working-age population with a higher education, completed or not. ETCR and EPL are, respectively, composite indicators of product and labour market rigidities.

Second, the price elasticity for ICT factors is allowed to change over time. This assumption is presented (without any empirical findings) by Oulton (2002). This reflects the fact that ICT diffusion, linked to improved productivity, corresponds both to a widening of ICT diffusion (ICT equipment is installed in places where there was none before) and an intensification of this diffusion (replacement of obsolete ICT equipment by new and more efficient equipment). Given that the first effect is gradually subsiding while the second is still supporting ICT growth, the overall result is a slowdown in ICT diffusion and a decrease (in absolute terms) in the price elasticity of ICT demand.

We assume that the parameter values depend on the level of ICT diffusion. To deal with these changes, we introduce in the empirical specification an ICT diffusion threshold above which the parameters could become different. It is a simplistic method but compatible with the sample dimensions. With a well defined threshold it allows us to focus on the period with stable ICT capital coefficient and thus helps to explain the persistent ICT diffusion gaps between countries at the end of the sample period. For the ICT price elasticity an alternative method is also mobilised: a quadratic specification over time. This specification doesn't immediately depend on ICT diffusion, but it provides year specific ICT price elasticity estimates that we consider as an indicator for the gradual slowdown of the widening of ICT diffusion. In the following, the quadratic specification over time is preferred for the ICT price elasticity, but price elasticity changes are also supported by the Bai and Perron (1998) break test with an ICT diffusion threshold for this parameter. These changes lead to the second estimated relationship:

$$
\begin{aligned}
& f_{k, t}-q_{k, t}=a 1_{t} \cdot\left(c_{k, t}-p_{q k, t}\right)+a 2_{t} \cdot E D U C_{k, t}+a 2^{\prime} \cdot E D U C_{k, t}^{2}+a 3_{t} \cdot R_{I G I D_{k, t}}+ \\
& \sum_{i} b_{i, k} \cdot x_{i k, t}+c s t_{k}+u_{k, t}
\end{aligned}
$$


With the following assumptions:

$-\mathrm{a} 1_{\mathrm{t}}=\mathrm{a} 1+\mathrm{a} 1^{\prime} \cdot \mathrm{t}+\mathrm{a} 1^{\prime \prime} \cdot \mathrm{t}^{2}$

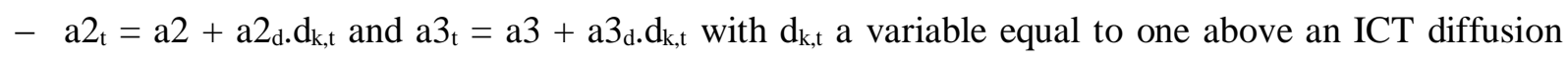
threshold and 0 otherwise.

\section{Estimating demand for ICT capital}

We first present the data used (3.1.), then the results (3.2.).

\subsection{Data}

The data construction, mainly based on the EU-KLEMS database, is detailed in Appendix A. A specific evaluation was conducted for certain variables -such as investment price deflators (used to calculate the investment volume), the productive capital stock and the capital user cost- based on calculation assumptions common to the different countries. Particularly, we assume that the ratio of ICT price to the GDP deflator in every country is the same as that in the United States. The reason for this convention is that the United States uses more advanced methodologies to take into account the quality improvements in goods, especially ICT. ${ }^{7}$ The relations are estimated on a country panel data of the eleven countries with sufficiently robust data: Austria, Denmark, Finland, France, Germany, Italy, Japan, the Netherlands, Spain, the United Kingdom and the United States over the 1981-2005 period.

\subsection{Estimation results}

According to the literature on ICT, the ICT capital coefficient and its relative user cost might be nonstationary. Im, Pesaran and Shin (2003) provide a panel unit-root test allowing for heterogeneity across individual roots. Despite the relatively weak time dimension of the data, this test confirms that these variables are integrated of order one, I(1). Using I(1) variables the 'spurious regression problem' may be suspected. However, the ICT capital coefficient and relative user costs seem to be cointegrated, according to the cointegration tests from Pedroni $(1995,2004)$ (methods and results are presented in appendix C), thus allowing us to estimate equation (2) or (3).

Table I shows the results from the estimation of relationships (2) and (3). These estimates were obtained using the ordinary least squares method (OLS) or the instrumental variable method (IV) in order to deal with measurement errors such as white noise or those corresponding to a simultaneity bias. The instrumented variables are the ICT capital user cost, the average age of capital and the production capacity utilisation rate. Among the many sets of instruments alternatively tested, the instruments finally used are the only ones satisfying both the Sargan test of exogeneity (1958) and the Davidson and MacKinnon test (1993) of convergence of the ordinary least square estimator. ${ }^{8}$ These instruments are the first differences of the instrumented variables lagged by one and two periods. The relevance of the instruments is confirmed by the Nelson and Startz (1990) F-test. The estimation results are robust to the estimation method (OLS or IV).

An important step of the estimation of the relation (4) is choosing the ICT diffusion threshold (above which the variable $\mathrm{d}$ is equal to one, and zero otherwise). The threshold is selected by scanning, the selection criteria being the minimisation of the sum of the squared estimation residuals. It should be noted that whatever the threshold scanned, the tests of equality of the coefficients below

7 A discussion on how to take account of cross-country methodological differences in price deflators for computers is available in Schreyer (2000).

8 The sets of instruments tested are combinations of the following variables lagged one or more periods: the explanatory variables or their first difference, long-term or short-term interest rates on treasury bonds, alternative capital user costs, the unemployment rate, the participation rate and the proportion of civil servants in global employment. 
and above the threshold always reject the null hypothesis of equality for ICT capital demand. ${ }^{9}$ The selected threshold is $3.5 \%$. For the mobilized data, the percentage of observations above this threshold is $30.9 \%$ over the whole period $1981-2005,76.5 \%$ in the last ten years 1996-2005 and $100 \%$ in the last year $2005 .{ }^{10}$ The estimates are robust to the chosen threshold (see Appendix D).

The ICT price elasticity is statistically significant and shows a negative sign, as expected. The assumption that the price elasticity of demand for ICT is quadratic over time is confirmed by the statistically significant parameters measuring this specific trend. The estimations show a decrease over time (in absolute terms) of the price elasticity of demand for ICT (Figure 4). This price elasticity is close to -2 at the beginning of the 1980 s and close to -1 in the middle of the $2000 \mathrm{~s} .{ }^{11}$ These estimates provide some empirical evidence that the broadening of ICT diffusion is gradually slowing, whereas the intensification of this diffusion continues to be in line with the increase in ICT performances. This slowdown could lead to the end of the contribution of ICT to growth. This seems fully consistent with the apparent stabilisation, in the last few years, of the ICT capital coefficient. These empirical results are, to our knowledge, original.

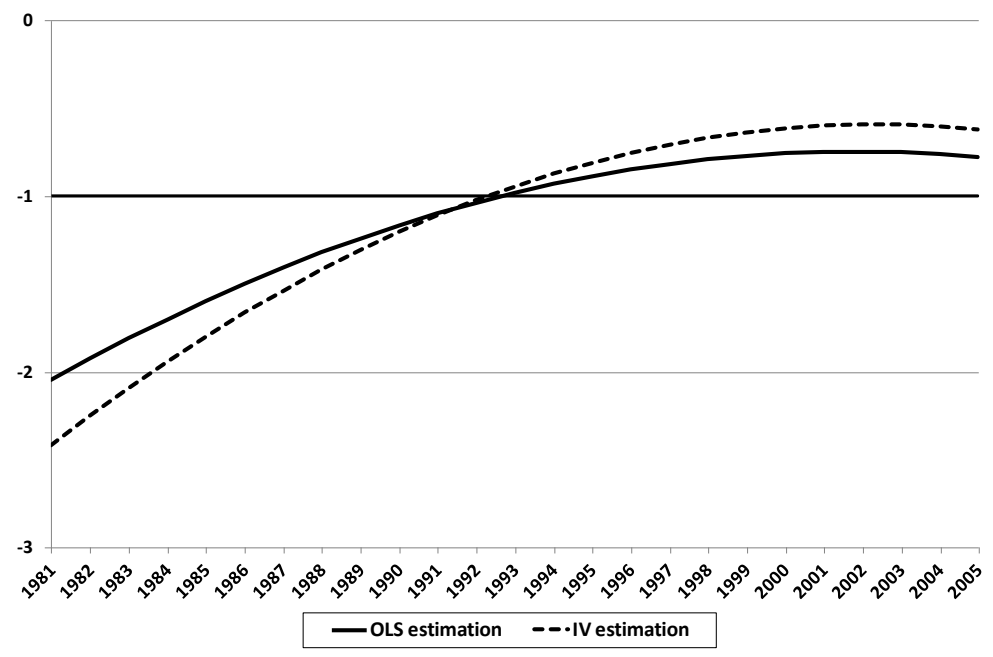

Figure 4. Estimates of the price elasticity of demand for ICT capital Results from the estimation of relationship (3), using the OLS method (results provided in Table I column [2]) or the IV method (Table I column [3]).

As regards education, the greater the share of the population with a higher education, the greater the ICT diffusion. The impact of the level of education on ICT diffusion is stronger when ICT diffusion is already substantial. The impact of market rigidities is significant only if the ICT diffusion threshold dummy is introduced in the estimated relation (column [1] compared to [2] and [3]). When it is the case, labour and product market rigidity indicators (EPL and ETCR, respectively) and their interaction have adverse and significant effects on ICT diffusion (column [2] to [5]). This adverse effect is amplified above the ICT diffusion threshold (column [2] and [5]).

9 As the ICT diffusion threshold is chosen from a statistic selection method, the t-statistics of the parameters a5ICT' and a7ICT' showed in Table 1 are irrelevant to conclude on the evolution of the impact of education and rigidities on ICT demand. Nevertheless, as the null hypothesis of equality could be rejected whatever the threshold tested, the statistical significativity of the evolution is not reassessed by the choice of a particular threshold.

10 In addition, this threshold is reached in 1995 for Denmark, in 1996 for the United States, in 1997 for the United Kingdom and Japan, in 1998 for the Netherlands, in 1999 for Finland and Germany and in 2000 for Austria, Spain, France and Italy.

11 When ICT price elasticity changes are specified via an ICT diffusion threshold, the evolution is confirmed by the Bai and Perron (1998) break test. 
Table I. Results from the estimation of relationship (2) and (3)

\begin{tabular}{|c|c|c|c|c|c|c|}
\hline & & [1] & [2] & [3] & [4] & [5] \\
\hline $\begin{array}{l}\text { Market } \\
\text { indicator }\end{array}$ & & & EPL*ETCR & & EPL & ETCR \\
\hline Estimati & nethod & OLS & OLS & IV & OLS & OLS \\
\hline & 1 & $-1.137 * * *$ & $-2.051 * * *$ & $-2.422 * * *$ & $-2.092 * * *$ & $-2.073 * * *$ \\
\hline 胥 & & [0.073] & [0.112] & [0.188] & [0.116] & [0.113] \\
\hline 产 & a1, & & $0.125 * * *$ & $0.171 * * *$ & $0.123 * * *$ & $0.122 * * *$ \\
\hline 8 & & & [0.015] & [0.042] & [0.015] & [0.015] \\
\hline & a1" & & $-0.003 * * *$ & $-0.003 * * *$ & $-0.003 * * *$ & $-0.003 * * *$ \\
\hline & & & {$[0.000]$} & {$[0.001]$} & {$[0.000]$} & {$[0.000]$} \\
\hline & ? & $5.362 * * *$ & $9.551 * * *$ & $7.347 * * *$ & $10.203^{* * *}$ & $9.704 * * *$ \\
\hline Е & & [1.801] & [1.667] & [2.935] & [1.761] & [1.730] \\
\hline 荀 & $\mathrm{a} 2_{\mathrm{d}}$ & & $1.448 * * *$ & $1.018 * * *$ & $1.255^{* * *}$ & $1.663 * * *$ \\
\hline 3 & & & {$[0.266]$} & [0.389] & {$[0.275]$} & [0.316] \\
\hline & a2, & $-8.994 * *$ & $-15.028 * * *$ & $-13.036^{* * *}$ & $-14.990 * * *$ & $-15.944 * * *$ \\
\hline & & [4.328] & [4.161] & [4.766] & [4.249] & [4.235] \\
\hline & a3 & 0.041 & $-0.149 * * *$ & $-0.068^{*}$ & $-0.109 * *$ & -0.232 \\
\hline 象 & & [0.049] & [0.040] & [0.039] & [0.053] & [0.154] \\
\hline$\sum^{\sigma}$ & 3 & & $-0.224 * * *$ & $-0.094 * * *$ & $-0.078 * * *$ & $-0.547 * * *$ \\
\hline & & & [0.045] & [0.047] & [0.023] & {$[0.124]$} \\
\hline Sargan $t$ & & & & & & \\
\hline & & & & 4.835 & & \\
\hline & & & & 0.3048 & & \\
\hline Davidsor & MacK & on test & & & & \\
\hline & & & & 11.24 & & \\
\hline & & & & 0 & & \\
\hline Observa & & 275 & 275 & 275 & 275 & 275 \\
\hline $\mathbf{R}^{2}$ & & 0.95 & 0.97 & 0.95 & 0.97 & 0.97 \\
\hline
\end{tabular}

Standard errors in brackets. * significant at $10 \%$; ** significant at $5 \%$; *** significant at $1 \%$.

List of instruments: $\Delta \mathrm{c}_{\mathrm{k}, \mathrm{t}-1}, \Delta \mathrm{c}_{\mathrm{k}, \mathrm{t}-2}, \Delta \mathrm{AGE}_{\mathrm{k}, \mathrm{t}-1}, \Delta \mathrm{AGE}_{\mathrm{k}, \mathrm{t}-2}, \Delta \mathrm{CUR}_{\mathrm{k}, \mathrm{t}-1}, \Delta \mathrm{CUR}_{\mathrm{k}, \mathrm{t}-2}$.

In order to simplify the presentation, the estimated coefficients of certain variables used in the estimations (CUR, AGE, chg and country fixed-effects) are not shown in the above Table.

\section{Policy implications and concluding remarks}

Compared with the large body of literature on the ICT diffusion process, this analysis provides some original results. Firstly, the estimates show that the impact of the proportion of the population with a higher education and of market rigidities on ICT diffusion increases with the level of ICT diffusion. These results are consistent but more comprehensive than those obtained by Aghion et al. (2008). Secondly, the estimates also show for every country a decrease over time (in absolute terms) in the price elasticity of the demand for ICT. This suggests that ICT diffusion reflects both a widening of ICT diffusion and an intensification of this diffusion. The first effect is gradually subsiding while the second remains supportive of ICT growth. The overall result is a slowdown in ICT diffusion and a decrease in the price elasticity of ICT demand (in absolute terms).

The estimates strongly confirm the idea that the persistent ICT diffusion differences between the main advanced countries can largely be explained by differences in the education level of the workingage population and in market rigidities. They provide useful insights for economic policy, as they make it possible to quantify the effects to be expected, in terms of ICT diffusion, from an increase in the share of the working-age population with a higher education or from a decrease in product and labour market rigidities. Figure 5 shows the ICT capital coefficient gains for each country from adopting the US labour and product market regulations as well as the US level of higher education in 
2005. Such a scenario corresponds to an illustrative unrealistic extreme case. The gains from adopting US values are calculated according to the estimates of Table I, column [3]. On average, the potential gains from educational catch-up are more or less equivalent to the gains from reforming market rigidities ( 0.87 and 0.74 point of percentage, respectively). There are important gains differences between countries, but the increases in ICT capital coefficient are high in all countries: from 0.69 of a percentage point in Finland to 2.85 percentage points in Italy. There is therefore a major reserve of ICT capital coefficient gains that structural reforms could release, thereby substantially reducing the ICT diffusion gaps between industrialised countries and the United States.

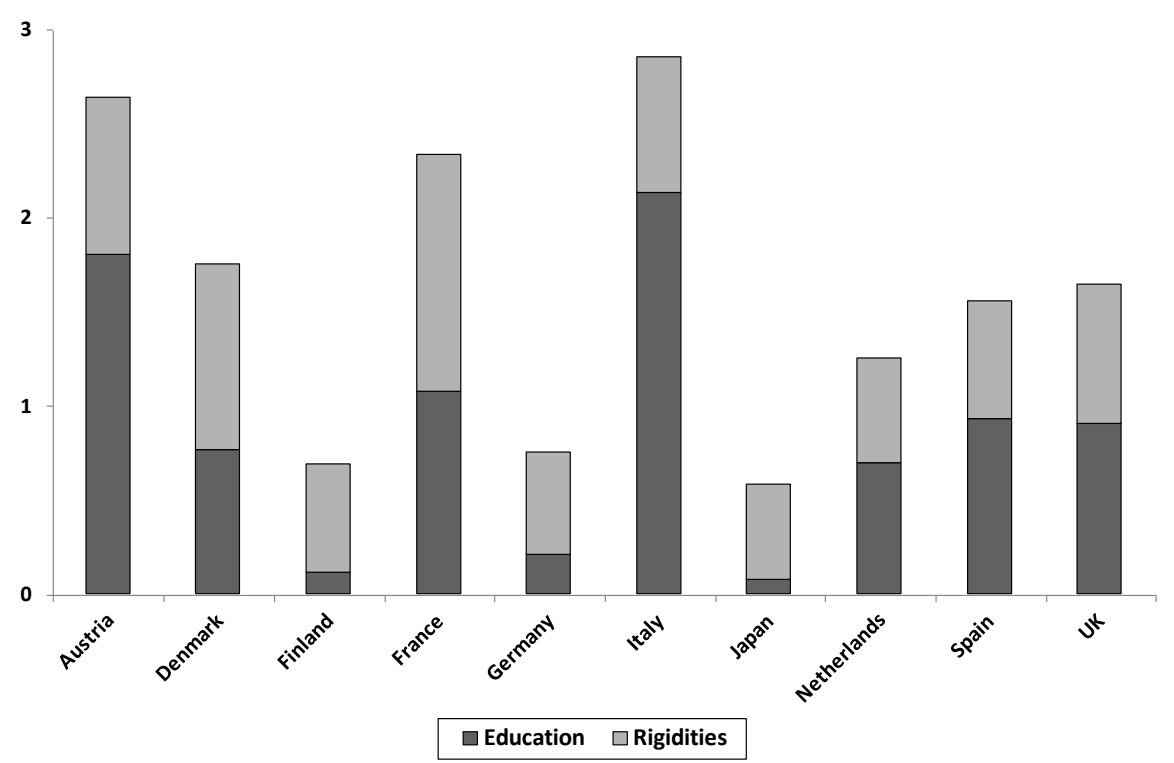

Figure 5. ICT capital coefficient gains from adopting the US values of market rigidities and education In 2005 - In percentage points

These impacts on ICT capital coefficients are calculated on the basis of an estimation of relationship (3), using the IV method (results provided in Table I column [3]).

The cross-country differences stemming from the user costs are negligible and are not taken into account in this graph.

The robustness of the results and, consequently, of the lessons to be drawn need confirmation by other empirical analyses based on industry or firm level data. In particular, explanations of the parameter changes should be explored. We provide one interpretation for the decrease over time (in absolute terms) of the ICT price elasticity. As final remarks, we propose explanations for the heightened impact of the level of education and market rigidities when ICT diffusion is high: (i) if ICT capital is complementary to educated workers, the national level of education could be a stronger limitation for ICT diffusion when educated workers are already absorbed by ICT previously installed; (ii) if ICT equipments are first installed in places where their efficient use don't require organizational changes or other important costs, then market rigidities would impact ICT diffusion only in a second step, when ICT diffusion is widened to other places. However, these explanations are neither supported nor invalidated by our empirical investigation and much more research needs to be carried out. 


\section{References}

Aghion P., P. Askenazy, R. Bourlès, G. Cette and N. Dromel. 2008. Education, Market Rigidities and Growth. Economics Letters 102: 62-65.

Amable, B. and D. Gatti. 2006. Labor and product Market Reforms: Questioning Policy Complementarity. Industrial and Corporate Change 15, no.1: 101-122.

Antipa, P., G. Cette, L. Frey, R. Lecat and O. Vigna. 2007. Evolutions récentes de la productivité : accélération structurelle dans la zone euro et ralentissement structurel aux Etats-Unis ?. Banque de France Bulletin 164, August.

Antonelli, C., J. Krafft and F. Quatraro. 2010. Recombinant Knowledge and Growth: The Case of ICTs. Structural Change and Economic Dynamics 21.

Autor, D., L. Katz and M. Kearney. 2006. The Polarization of the U.S. Labor Market. American Economic Review 96, no. 2.

Arduini, D., L. Nascia and A. Zanfei. 2010. Complementary Approaches to the Diffusion of ICT: Empirical Evidence on Italian Firms. University of Urbino Carlo Bo, Department of Economics Working Papers 1002.

van Ark, B., R. Inklaar and R. McGuckin. 2002b. Productivity, ICT and Services Industries: Europe and the United States. Mimeo, Groningen Growth and Development Center.

van Ark, B., J. Melka, N. Mulder, M. Timmer and G. Ypma. 2002a. ICT investment and growth accounts for the European Union, 1980-2000. Mimeo, June.

van Ark, B., M. O’Mahoney and M. P. Timmer. 2008. The Productivity Gap between Europe and the United States: Trends and Causes. The Journal of Economic Perspectives 22, no. 1.

Bai, J. and P. Perron. 1998. Estimating and testing linear models with multiple structural changes. Econometrica 66, no. 1: 47-78.

Blanchard, O. 2005. European Unemployment: the evolution of fact and ideas. NBER Working Paper 11750, Cambridge Mass.

Blanchard, O. and F. Giavazzi. 2003. Macroeconomic effects of regulation and deregulation in goods and labor markets. Quarterly Journal of Economics, 879-907.

Cette, G., J. Lopez and P.-A. Noual. 2005. Investment in Information and Communication Technologies: an empirical analysis. Applied Economics Letters 12, no. 5.

Conway P., V. Janod and G. Nicoletti. 2005. Product Market Regulation in OECD Countries. OECD Working Paper.

Colecchia, A. and P. Schreyer. 2001. ICT Investment and Economic Growth in the 1990s: Is the United States a Unique Case?. OECD, DSTI/DOC(2001)7.

Davidson, R. and J. MacKinnon. 1993. Estimation and Inference in Econometrics. Oxford University Press.

Gust, C. and J. Marquez. 2000. Productivity Developments Abroad. Federal Reserve Bulletin, October.

Gust, C. and J. Marquez. 2004. International Comparisons of Productivity Growth: The Role of Information Technology and Regulatory Practices. Labour Economics 11.

Haller, S. and I. Siedschlag. 2008. "Determinants of ICT Adoption: Evidence from Firm Level Data., The Economic and Social Research Institute Working Papers 29.

Im K., M. H. Pesaran and Y. Shin. 2003. Testing for Unit Roots in Heterogeneous Panels. Journal of Econometrics 115, no. 1.

Jorgenson, D.W. and Z. Griliches. 1967. The Explanation of Productivity Change. Review of Economic Studies 34.

Koeniger, W. and A. Vindigni. 2003. Employment Protection and Product Market Regulation. IZA Discussion Papers 880.

Lera-Lopez, F., M. Billon and M. Gil. 2011. Determinants of Internet Use in Spain. Economics of Innovation and New Technology 20, no. 2.

Nelson, C.R. and R. Startz. 1990. The Distribution of the Instrumental Variables Estimator and its t-Ratio when the Instrument is a Poor One. Journal of Business 63, no. 1.

OECD. 1999. OECD Employment Outlook 1999.

OECD. 2002. Measuring the Information Economy. Mimeo.

OECD. 2003. ICT and Economic Growth: Evidence from OCDE Countries, Industries and Firms. Mimeo.

Oulton, N. 2002. ICT and Productivity Growth in the United Kingdom. Oxford Review of Economic Policy 18, no. 3.

Pedroni, P. 1995. Panel cointegration, asymptotic and finite sample properties of pooled time series tests with an application to the PPP hypothesis. Working Paper in Economics 92-013, Indiana University.

Pedroni, P. 2004. Panel Cointegration: Asymptotic and Finite Sample Properties of Pooled Time Series Tests with an Application to the PPP Hypothesis. Econometric Theory 20, no. 3.

Pilat, D. and F. C. Lee. 2001. Productivity growth in ICT-producing and ICT-using industries: a source of growth differentials in the OECD?. Mimeo, DSTI/DOC(2001)4. 
Sargan, J. 1958. The Estimation of Economic Relationships Using Instrumental Variables. Econometrica 26: $393-415$

Shreyer, P. 2000. The contribution of Information and Communication Technology to Output Growth: A Study on the G7 Countries. OECD, STI Working Paper, 200/2.

Siedschlag, I., X. Zhang and D. Smith. 2009. What Determine the Attractivenes of EU Regions to the Location of Multinationals in the ICT Sector?. The Economic and Social Research Institute Working Papers 45. 


\section{Appendix}

\section{Appendix A: Data sources and calculations of capital coefficients and user costs}

ICT investment and output in current prices come from the University of Groningen's database and are available from 1970 to 2004 (as well as the number of person engaged and labour remuneration). ${ }^{12}$ These data are homogenised across countries. Only the "Total Economy" level is used in the empirical analysis. Three ICT assets were available: computing equipment, software and communication equipment. According to our descriptive analysis, the breakdown between the three assets differs too greatly across countries. Therefore, only the sum of the different investment is used.

Asset prices may not take proper account of the changes in ICT asset performances. In order to consider this issue, the investment price deflators used to calculate the investment in volume are computed from the US prices. In every country, it is assumed that the ICT prices relative to the GDP deflator are the same as in United States. The reason for this convention is that the United States uses more advanced methodologies (see Schreyer 2000). ${ }^{13}$ Then, the ICT capital stock is calculated from a perpetual inventory method (PIM) with constant geometric depreciation rates specific to each ICT asset, according to the following equation:

$$
K_{t}=(1-\delta) \cdot K_{t-1}+I_{t-1}
$$

where $K$ is the capital stock and $I$ the investment, both in volume, and $\delta$ the depreciation rate.

The ICT capital user costs come from the first order conditions of the producer maximisation programme (see Jorgenson and Griliches, 1967):

$$
C_{t}=p_{I C T t-1} \cdot\left(r+\delta-\Delta \ln \left(p_{I C T}\right)\right)
$$

where $r$ is the long-term nominal interest rate on treasury bill (from OECD database).

\section{Appendix B: The demand for factors}

The equations of demand for factors relative to the output price $\left(P_{q}\right)$ and volume $(Q)$ are specified in two steps.

First, pair demands for factors relative to each other are deduced from a Constant Elasticity of Substitution (CES) production function. Indeed, the first-order conditions of the producer maximisation programme imply:

$$
\frac{F_{j}}{F_{i}}=\operatorname{CST} \cdot\left(\frac{C_{i}}{C_{j}}\right)^{\sigma_{i j}} \Leftrightarrow f_{i}=f_{j}-\sigma_{i j} \cdot\left(c_{i}-c_{j}\right)+c s t
$$

where $C_{i}$ is the user cost of factor $i, \sigma_{i j}$ the elasticity of substitution between $i$ and $j, F_{i}$ the volume of factor $i$ and CST a constant term. Small letters indicates the logarithm of the variables. Time and country indices are not indicated without loss of clarity.

Then, the relations between the volumes of each factor and the output stem from two assumptions:

- the production function is log-linearized by approximation: $q \approx \sum_{i} \alpha_{i} . f_{i}+c s t$, with $\alpha_{i}$ the output elasticity with the factor $i$.

- $\quad p_{q}=\frac{\sum_{i} \alpha_{i} \cdot \sigma_{i j} \cdot c_{i}}{\sum_{i} \alpha_{i} \cdot \sigma_{i j}}$. This assumption is less intuitive. The output price depends on a weighted average of the factor user costs. With a Cobb-Douglas production, perfect product markets and constant returns to scale, $a 1_{i} \equiv \sum_{i} \alpha_{i} . \sigma_{i j}$ is equal to one and this relation is always true. The further from this particular case the stronger the assumption is.

According to these assumptions, the ICT demand is: $f_{i}=q+a 1_{i} \cdot\left(c_{i}-p_{q}\right)+$ cst with $i=$ TIC

12 Capital services in the EU-KLEMS database are calculated from these investment series.

13 Additional variables are introduced in the estimated equation because of this data treatment. 


\section{Appendix C: Pedroni (1995, 2004) cointegration tests}

The ICT capital coefficient is integrated of order one (I(1)). If it induces non-stationarity residual terms in the estimated relations (2) or (3), then the standard error estimates don't converge to their true values. It is the socalled 'spurious regression problem'. ${ }^{14}$ However, if the dependant variable and the explicative variables share the same stochastic trends, residual terms would be stationary and the cointegration between the variables could be estimated. Pedroni $(1995,2004)$ introduces seven statistics to test the null hypothesis of no-cointegration against the alternative hypothesis of cointegration of the variables for every individual. Under the alternative hypothesis, four 'Panel statistics' assume identical autoregressive coefficients for every individual, whereas the three 'Group statistics' avoid this constraint. We use these statistics to test a cointegration relation between the ICT capital coefficient and its relative user cost. The economic insight is that the non-stationarity of the capital coefficient is caused by the stochastic trends of the user cost, but we can test only for correlation. The results are presented in Table II.

Table II. Pedroni $(1995,2004)$ cointegration tests between the ICT capital coefficient and its relative user cost, on the 1981-2005 period

\begin{tabular}{|c|c|c|}
\hline Panel statistics : & Statistic & P-value \\
$-\quad$ Variance ratio type & 4.217 & 0.000 \\
$-\quad$ Phillips-Perron $\rho$ type & -1.924 & 0.063 \\
$-\quad$ Phillips-Perron $t$ type & -3.253 & 0.002 \\
$-\quad$ Augmented-Dickey-Fuller type & -3.393 & 0.001 \\
\hline Group statistics : & -0.585 & \\
$-\quad$ Phillips-Perron $\rho$ type & -3.068 & 0.336 \\
- Phillips-Perron $t$ type & -3.222 & 0.004 \\
\hline
\end{tabular}

Tests specifications with a constant, a trend and maximum of three lags.

The null hypothesis of no-cointegration is rejected by six of the tests (five at a $1 \%$ threshold and one at $10 \%$ ). The sample dimension could explain the different result with the Phillips-Perron group- $\rho$ statistics. From these tests we conclude on the cointegration of the ICT capital coefficient and its user cost.

\section{Appendix D: Robustness to the ICT diffusion threshold}

The changes in the parameters according to ICT diffusion are dealt with a threshold. The tests of equality of the coefficients below and above this threshold always reject the null hypothesis of equality whatever the threshold chosen (with enough observations below and above). Moreover the estimations results are robust to this choice. For each threshold the impact of the level of education and of market rigidities on ICT capital coefficient is heightened when the ICT diffusion is already high. Furthermore, the impacts above the threshold and the differences between the parameters below and above the threshold are growing with the level of ICT diffusion chosen as threshold.

14 In panel data regressions, the estimated coefficients of the explicative variables impacts are still convergent with nonstationary residual terms, on the contrary to time series regressions, but without convergent standard errors estimates the statistical significance of the coefficients cannot be evaluated. 
Table III. Results from the estimation by OLS of relationship (3) with the market rigidity indicator EPL*ETCR

\begin{tabular}{|c|c|c|c|c|c|c|}
\hline \multirow{2}{*}{\multicolumn{2}{|c|}{$\begin{array}{l}\text { ICT diffusion threshold } \\
\text { tTThreshold }\end{array}$}} & [1] & [2] & [3] & [4] & [5] \\
\hline & & $2.5 \%$ & $3 \%$ & $3.5 \%$ & $4 \%$ & $4.5 \%$ \\
\hline \multirow{6}{*}{ 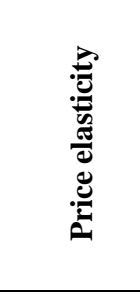 } & \multirow{2}{*}{ a1 } & $-2.127 * * *$ & $-2.110^{* * *}$ & $-2.051 * * *$ & $-2.067 * * *$ & $-2.045^{* * *}$ \\
\hline & & [0.110] & [0.112] & [0.112] & [0.111] & [0.109] \\
\hline & \multirow{2}{*}{ a1' } & $0.135 * * *$ & $0.129 * * *$ & $0.125 * * *$ & $0.129 * * *$ & $0.123 * * *$ \\
\hline & & [0.015] & {$[0.015]$} & {$[0.015]$} & [0.014] & [0.014] \\
\hline & \multirow{2}{*}{ a1" } & $-0.003 * * *$ & $-0.003 * * *$ & $-0.003 * * *$ & $-0.003 * * *$ & $-0.003 * * *$ \\
\hline & & {$[0.000]$} & {$[0.000]$} & {$[0.000]$} & [0.000] & {$[0.000]$} \\
\hline \multirow{6}{*}{ 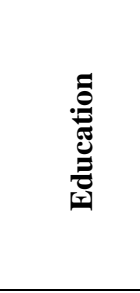 } & \multirow{2}{*}{$\mathbf{a} 2$} & $7.869 * * *$ & $9.005 * * *$ & $9.551 * * *$ & $9.678 * * *$ & $9.530 * * *$ \\
\hline & & [1.684] & [1.646] & [1.667] & [1.734] & [1.714] \\
\hline & \multirow{2}{*}{$\mathbf{a} 2_{d}$} & $-0.090 * *$ & $-0.122 * * *$ & $-0.149 * * *$ & $-0.144 * * *$ & $-0.146^{* * *}$ \\
\hline & & [0.040] & [0.039] & [0.040] & [0.042] & {$[0.043]$} \\
\hline & \multirow{2}{*}{ a2' } & $1.274 * * *$ & $1.325^{* * *}$ & $1.448 * * *$ & $1.533 * * *$ & $1.606^{* * *}$ \\
\hline & & [0.269] & [0.255] & {$[0.266]$} & [0.282] & {$[0.288]$} \\
\hline \multirow{4}{*}{ 总: } & \multirow{2}{*}{ a3 } & $-11.238 * * *$ & $-14.383 * * *$ & $-15.028 * * *$ & $-14.751 * * *$ & $-14.576^{* * * *}$ \\
\hline & & [4.207] & [4.168] & [4.161] & [4.241] & [4.214] \\
\hline & \multirow{2}{*}{$\mathbf{a 3}_{\mathrm{d}}$} & $-0.088 * * *$ & $-0.171 * * *$ & $-0.224 * * *$ & $-0.202 * * *$ & $-0.208 * * *$ \\
\hline & & {$[0.032]$} & {$[0.036]$} & {$[0.045]$} & {$[0.053]$} & [0.058] \\
\hline \multicolumn{2}{|c|}{ Observations } & 275 & 275 & 275 & 275 & 275 \\
\hline \multicolumn{2}{|l|}{$\mathbf{R}^{2}$} & 0.97 & 0.97 & 0.97 & 0.97 & 0.97 \\
\hline
\end{tabular}

Standard errors in brackets. * significant at 10\%; ** significant at 5\%; *** significant at $1 \%$ In order to simplify the presentation, the estimated coefficients of certain variables used in the estimations (CUR, AGE, chg and country fixed-effects) are not shown in the above Table. 